\title{
Enfermedad de Caroli
}

\author{
Caroli's disease \\ Rafael Flores Suárez, ${ }^{*, \neq}$ Martha Nidia Merino Sequeira, ${ }^{*, \$}$ \\ Blanca Ruiz Sierra, ${ }^{*}$ " Heber Trinidad Alonso Quell \\ Citar como: Flores SR, Merino SMN, Ruiz SB, Alonso QHT. Enfermedad de Caroli. Acta \\ Med. 2021; 19 (1): 138-139. https://dx.doi.org/10.35366/98588
}

Hombre de 33 años, sin antecedentes de importancia, se presenta por cuadro de dolor abdominal en epigastrio, acompañado de fiebre, cefalea, vómito, coluria y evacuaciones diarreicas de una semana de evolución.

Se presentan imágenes de tomografía contrastada de abdomen, donde se identifica hígado aumentado de tamaño, con parénquima heterogéneo, con múltiples imágenes hipodensas de aspecto ovoideo y de distribución difusa y esplenomegalia (Figura 1). La enfermedad de Caroli fue descrita en 1958 por el médico francés Jacques Caroli, también conocida como "ectasia cavernosa comunicante congénita del árbol biliar". Es una enfermedad congénita rara, de patrón autosómico recesivo, que afecta a uno de cada millón de habitantes con mayor prevalencia en la población femenina, con una frecuencia con respecto a los varones de 1.8:1.1-4

La enfermedad de Caroli forma parte de las enfermedades fibroquísticas del hígado y se incluye dentro del grupo V de la clasificación de Todani con relación a dilatación de la vía biliar intrahepática. 1,4,5 Se caracteriza por la dilatación focal o multifocal de los conductos biliares intrahepáticos, de distribución difusa o localizada. ${ }^{2}$

Si bien su fisiopatología no es aún totalmente comprendida, se sabe que está asociada al gen PKHD1, mismo

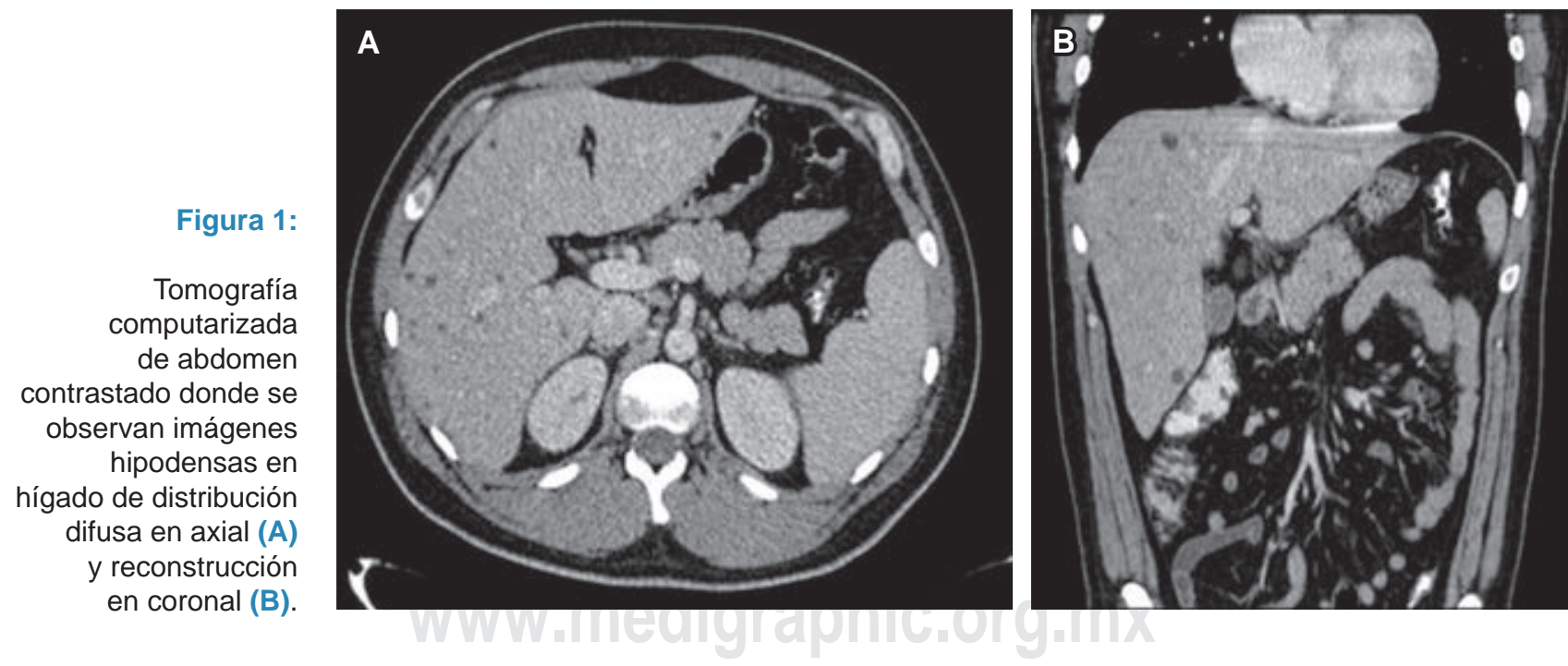

* Facultad de Medicina de la UNAM. Hospital Ángeles Pedregal. CDMX, México.

* Médico Residente de Imagenología Diagnóstica y Terapéutica.

§ Médico Radiólogo con Alta Especialidad en Radiología de Urgencias.

^ Médico Radiólogo con Alta Especialidad en Imagen Seccional.

\| Médico Radiólogo, Médico adscrito al Servicio de Radiología e Imagen del Hospital Ángeles Clínica Londres. CDMX, México.
Correspondencia:

Rafael Flores Suárez

Correo electrónico: rafafloresuarez@gmail.com

Aceptado: 07-04-2020.

www.medigraphic.com/actamedica

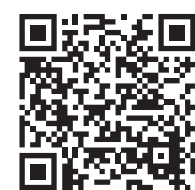



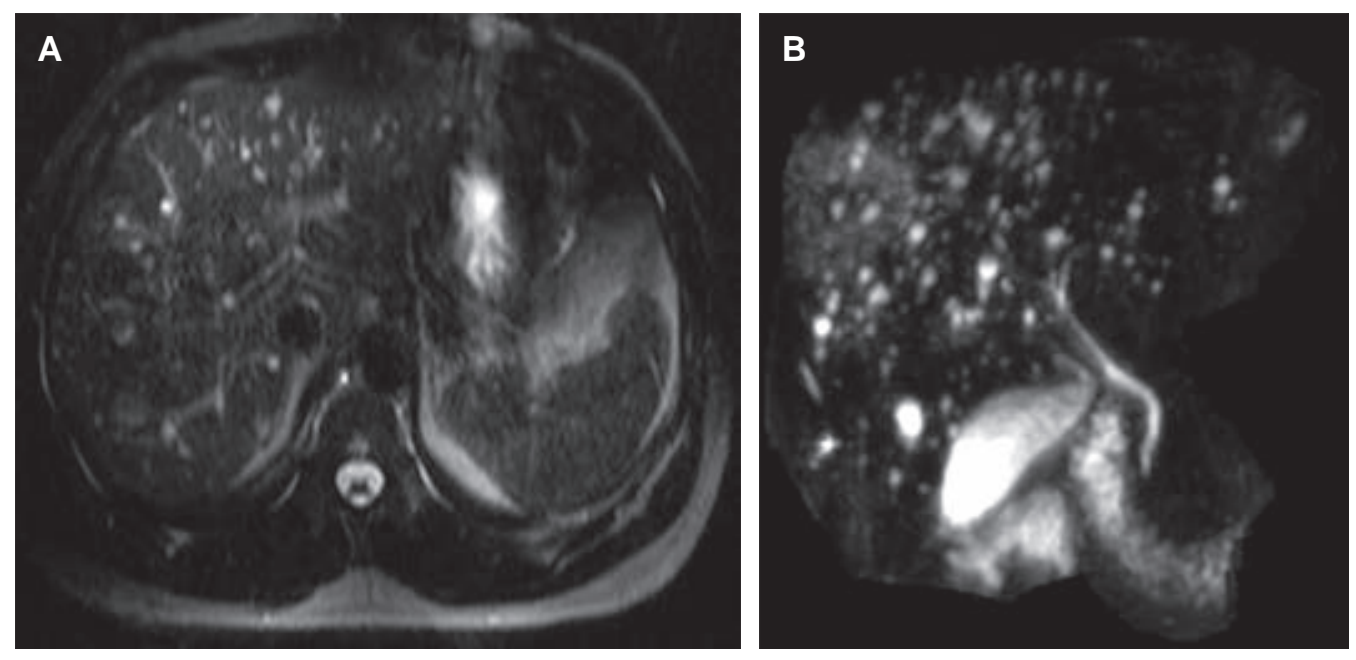

Figura 2:

A) Resonancia magnética en plano axial, potenciado en T2 donde se observan imágenes hiperintensas de distribución difusa en parénquima hepático.

B) Reconstrucción en plano coronal que muestra lesiones quísticas que se comunican con el árbol biliar.

que afecta la fibrocistina, proteína que se expresa en los colangiocitos hepáticos, alterando así el desarrollo del epitelio biliar con la consecuente involución de las placas ductales embrionarias y la formación de quistes adyacentes a la tríada portal. 1,2,4,6

Los pacientes afectados suelen cursar de manera asintomática hasta la segunda o tercera década de la vida, pudiendo incluso llegar a ser diagnosticados de forma incidental por medio de estudios de imagen. ${ }^{2,4}$ Típicamente inician con un cuadro inespecífico caracterizado por dolor abdominal en hipocondrio derecho así como prurito, fiebre e ictericia, para posteriormente presentar datos de colestasis y colangitis. ${ }^{1-4}$ Los estudios de laboratorio suelen revelar niveles elevados de bilirrubina directa, aspartato aminotransferasa (AST), alanina aminotransferasa (ALT) y fosfatasa alcalina (FA). 2,3 Complicaciones tales como la cirrosis biliar, abscesos hepáticos y septicemia son frecuentes; sin embargo, las complicaciones más graves son el desarrollo de falla hepática y/o cáncer biliar en pacientes crónicos. 1,2

El diagnóstico por imagen se puede realizar por diversos estudios tales como ultrasonido y tomografía computarizada (TC); sin embargo, la colangiopancreatografía por resonancia magnética (MRPC, por sus siglas en inglés) es actualmente el método de elección debido a su elevada especificidad y sensibilidad. ${ }^{2,4}$ En estudios realizados con TC podemos observar la mencionada dilatación de los con- ductos biliares intrahepáticos como imágenes hipodensas, de bordes definidos y de densidad líquida, distribuidas de manera difusa o focal (Figuras 1).1,2 Las imágenes obtenidas por medio de MRPC mostrarán múltiples lesiones de naturaleza quística de diversos tamaños que se comunican con el árbol biliar y que presentan una alta intensidad, al ser imágenes potenciadas en T2 (Figura 2). 1,3

El pronóstico de cada paciente depende del grado de afectación y número de órganos involucrados. A pesar de que existen múltiples terapias, tales como la colocación de un catéter transhepático o el uso de ácido ursodesoxicólico, el trasplante hepático sigue siendo el único tratamiento definitivo. ${ }^{6}$

\section{REFERENCIAS}

1. Musa E, Sayedin A. Caroli disease: rarely seen associated disorders. European Society of Radiology. 2018; 125: 1-17.

2. Yadav P, Adhikari S, Pandit N, Awale L, Vasan K, Khadka S. Caroli's disease: a diagnostic challenge. Int Surg J. 2018; 5: 3750-3753.

3. Issar P, Issar SK. Caroli's disease. Indian J Gastroenterol. 2014; 33 (5): 500.

4. Cabral Correia P, Morgado B. Caroli's disease as a cause of chronic epigastric abdominal pain: two case reports and a brief review of the literature. Cureus. 2017; 9 (9): e1701.

5. Domínguez-Comesaña E. Dilataciones congénitas de la vía biliar. Cir Esp. 2010; 88 (5): 285-291.

6. Jalaluddin U, Savio J. Caroli disease. StatPearls [Internet]. Treasure Island (FL): StatPearls Publishing; 2020. 